\title{
Optimal Feedback Control of Nonlinear Variable-Speed Marine Current Turbine Using a Two-Mass Model
}

\author{
Rajae Gaamouche $^{1} \cdot$ Abdelbari Redouane $^{2} \cdot$ Imad El harraki $^{2} \cdot$ Bouchra Belhorma $^{3} \cdot$ Abdennebi El Hasnaoui $^{2}$
}

Received: 9 May 2019 / Accepted: 15 November 2019 / Published online: 30 June 2020

(C) The Author(s) 2020

\begin{abstract}
This paper presents a contribution related to the control of nonlinear variable-speed marine current turbine (MCT) without pitch operating below the rated marine current speed. Given that the operation of the MCT can be divided into several operating zones on the basis of the marine current speed, the system control objectives are different for each zone. To deal with this issue, we develop a new control approach based on a linear quadratic regulator with variable generator torque. Our proposed approach enables the optimization of the rotational speed of the turbine, which maximizes the power extracted by the MCT and minimizes the transient loads on the drivetrain. The novelty of our study is the use of a real profile of marine current speed from the northern coasts of Morocco. The simulation results obtained using MATLAB Simulink indicate the effectiveness and robustness of the proposed control approach on the electrical and mechanical parameters with the variations of marine current speed.
\end{abstract}

Keywords Marine current turbine $\cdot$ Two-mass model $\cdot$ Tip speed ratio $\cdot$ Linearization $\cdot$ Optimal control $\cdot$ Linear quadratic regulator (LQR)

\section{Introduction}

The majority of renewable energy sources, such as wind and solar energies, have a fluctuating character, which alters the quality of the power injected into the electrical grid (Kumar

\section{Article Highlights}

- A hydrodynamic model based on both a profile of the daily variation of marine current speed and the experimental results of Mason-Jones is proposed.

- A linearization technique to regulate the system around a specific oper ating point is applied.

- A new optimal control based on the LQR approach that achieves the optimization of the operation of the turbine is developed.

- The effectiveness and robustness of the proposed control approach are investigated.

Rajae Gaamouche

raja.escom@gmail.com

1 Electromechanics Department, Mohammadia School of Engineering, 10000 Rabat, Morocco

2 Electromechanics Department, National Superior School of Mines, 10000 Rabat, Morocco

3 National Centre for Energy Sciences and Nuclear Techniques, 10000 Rabat, Morocco et al. 2016; Anvari et al. 2016). In fact, the integration of these renewable sources into the electrical grid can lead to the major need for the adjustment of voltage and frequency to overcome eventual electrical disturbances (e.g., voltage droops and short circuits) (Antonova et al. 2012). By contrast, marine current energy is more stable than wind and solar energies and represents a promising solution to deal with the aforementioned issues (Melikoglu 2018; Chen et al. 2018). Indeed, marine current energy mainly originates from the tides, which are a direct result of the combination of the Earth's rotation and the gravitational forces exerted on a water body by the Moon and Sun (Hodur 1997). Thus, predicting the particular location of the main component of these currents for long time periods is possible (Hodur 1997; Rourke et al. 2010).

In addition, according to Thiébaut and Sentchev (2015), marine current resources are abundant in such a scale that their use for energy production can satisfy the world's energy demand. Marine current turbines (MCTs) are evolving rapidly because more reliable oceanographic data are available and all of the advanced techniques developed, tested, and applied for wind turbines can be adapted to MCTs even if the dynamics of tides are totally different from those of wind (Fox et al. 2018). 
In recent years, numerous studies of the hydrodynamic aspects (Mycek et al. 2014; Frost et al. 2015; Blackmore et al. 2016) and the design of specific generators for the marine environment (Benelghali et al. 2012; Seck et al. 2018; Chen et al. 2019) have been conducted. Meanwhile, other studies focus on the electronic part of power (Pham et al. 2017; Einrí et al. 2019; Omkar et al. 2019; Qian et al. 2019).

To improve the energy conversion performance of MCTs and ensure that tidal energy resources are costeffective, rotor speed regulation, which can be classified into two types, i.e., fixed and variable speeds, is investigated in this study. Jena and Rajendran (2015) and Kettache (Khettache 2019) conducted a comparative study between fixed-speed and variable-speed wind generators. The variable-speed wind turbine is more advantageous than the fixed-speed wind turbine because it increases the energy efficiency, improves the quality of the kinetic energy produced, and stabilizes the fluctuations of the voltage and power of the electrical grid.

In the context of wind turbine technologies, many command algorithms have been designed and developed in the past decades to optimize the operation of turbines to maximize the energy efficiency. These controllers can be classified into four categories, namely, optimal control, nonlinear control, predictive control, and fuzzy logic.

Liu et al. (2016) proposed a fuzzy logic controller for the wind turbine system to achieve the objective of maximum power extraction based on a two-mass model. Bassi et al. (Bassi and Mobarak 2017) examined the variablespeed wind turbine in full and partial load segments through predictive control. This approach considers the maximum power point, with the goal of maximizing the power generated by the wind turbine.

In the litrature, many controllers based on nonlinear control have been used to model wind turbines. Boukhezzar and Siguerdidjane $(2010,2011)$ used a nonlinear controller to deal with the wind power capture optimization problem while restricting transient loads on the drivetrain components. Prasad et al. (2019) developed a new control approach for the generations and loads in the integrated wind power system. This control approach is based on nonlinear control.

Finally, optimal control has been widely used to model and design the variable-speed wind turbine. Optimal control can be applied in two quadratic linear forms, namely, linear quadratic regulator (LQR) and linear quadratic Gaussian (LQG).

Barrera-Cardenas and Molinas (2012) applied the LQG control to model wind turbines. The proposed LQG control has shown useful properties, good performance, and robustness in controller design which has been applied to wind energy converter systems. Kumar and Stol (2010) proposed and tested the use of Simulink to simulate the LQR controller for wind turbines to achieve better rotor speed regulation. To maximize the energy generated from wind, Fakharzadeh et al. 2013) presented a linear control law using the LQR approach. Bayat and Bahmani (2017) addressed both the problems of power regulation and wind turbine control using the LQR approach feedback. Mahmoud and Oyedeji (2016) proposed a new voltage control scheme based on the LQR control design for a grid-connected wind farm. The proposed solution can be conveniently utilized for multi-input multi-output systems.

Although the control design is widely used in wind turbine technology, to the best of our knowledge, only a few studies considered the control of MCTs. Zhou et al. (2013) proposed two control strategies (i.e., speed control and torque control) for the power limitation of the MCT when the speed of the marine current exceeds the nominal value. The torque control strategy limits the generator power to a certain value during the dynamic process. However, the proposed control strategy limits only the power for the high-speed marine current. It does not deal with the entire range of variations of the marine current speed. Toumi et al. (2017) reported on speed control using only the classical proportionalintegral correctors. The design of this type of control is robust in the case where the MCT is coupled with the permanent magnet synchronous generator. Nevertheless, this type of control cannot maximize the energy efficiency of the MCT. To cope with these drawbacks, in this study, we propose an efficient LQR design for maximizing the power efficiency and energy capture of the MCT. Our decision to use this controller is motivated by the results obtained in the context of wind turbine technology.

The main contributions of this study are summarized as follows:

- We have used a profile of the daily variation of marine current speed in the northern coasts of Morocco;

- We have developed a hydrodynamic model based on the experimental results of Mason-Jones et al.;

- We have modeled flexible transmission using the twomass model;

- We have applied a linearization technique to regulate the system around a specific operating point;

- We have developed a new optimal control based on the LQR approach that achieves the optimization of the operation of the turbine;

- We have obtained the simulation results of the assembled system using MATLAB Simulink. 
The remainder of this paper is organized as follows: in Section 2, we describe the MCT system and the aerodynamic and two-mass models. In Section 3, we present the linearization model for the determination of a state space. In Section 4, we develop a new optimal control based on the LQR approach to find a compromise between the optimization of the energy generated by the turbine and the reduction of the load at the level of two-mass mechanical shaft. In Section 5, we provide an overview of the system control objective implementation of the MCT system in the low-speed and high-speed areas of the marine current. In Section 6, we validate our optimal control performance using MATLAB Simulink. Finally, in Section 7, we conclude this paper and indicate the direction of future work.

\section{Marine Current Turbine System Modeling}

The marine current energy conversion chain, which is a combination of three subsystems, is modeled in Figure 1:

1) The aerodynamic subsystem (Figure 1(a)) consists of several blades (mostly three blades) and a hub. The blades of the MCT extract the kinetic energy from the marine current and convert it into mechanical energy.

2) The mechanical subsystem (Figure 1(b)) is composed of the gearbox (also called the drivetrain). This subsystem transforms the rotation rate of the shaft from low rotational speed at the rotor side into high rotational speed at the generator side.

3) The electromechanical subsystem (Figure 1(c)) is composed of the generator and a power electronics module, which converts the mechanical energy at the turbine into electrical energy. This subsystem will not be modeled in this work. In fact, the dynamics of electrical machines and power electronics systems are faster than that of the other parts of the MCT. Consequently, the system will be considered a mechanical structure. Therefore, the dynamics of the generator can be disregarded. The $T_{\mathrm{em}}$ value of the generator is

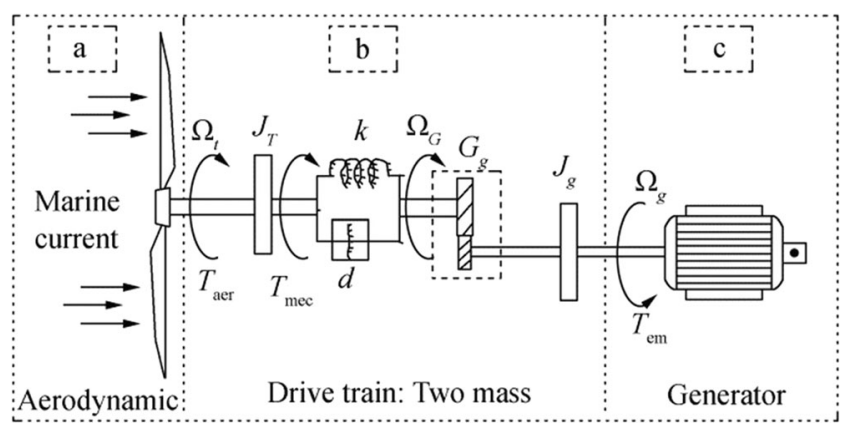

Figure 1 MCT model. (a) Aerodynamic system. (b) Drive train. (c) Generator considered equal to the reference value $T_{\mathrm{em}-\mathrm{ref}} P_{\mathrm{e}}$ is equal to the product of $T_{\mathrm{em}}$ and $\Omega_{\mathrm{g}}$ :

$P_{\mathrm{e}}=\Omega_{\mathrm{g}} \cdot T_{\mathrm{em}}$

We describe the model of each subsystem in the following subsections:

\subsection{Model of the Marine Current and Aerodynamic Subsystem}

\subsubsection{Model of the Resource}

Before installing the MCT, it is necessary to model the resources of the considered site. For this, the speed of the marine current can be predicted using two methods (Gaamouche et al. 2018):

1) Direct measurement: This method can be performed using conventional devices (e.g., helical current meters and acoustic doppler current profilers), a model proposed by the SHOM (French Naval Hydrographic and Oceanographic Service), or marine ships.

2) Modelization: Several techniques, such as harmonic analysis method, double cosine method, TideSim, and Tide $2 \mathrm{D}$, can be used to model marine currents.

The lack of data of marine current speed in Morocco leads to difficulties in utilizing this resource. Figure 2 presents the variation of marine current speed for a certain day in April 2018 in the northern coasts of the Moroccan kingdom near Spanish borders. The data measured by the European Marine Observation and Data Network were utilized in this study. This figure shows that we can launch such project in this region.

\subsubsection{Aerodynamic Modeling}

The aerodynamic power recovered by the rotor of the MCT can be expressed as follows:

$P=\frac{1}{2} \rho S V_{m}^{3}$

where $S=\pi \cdot R^{2}$ is the surface of turbine rotation and $\rho$ is approximately equal to $1024 \mathrm{~kg} / \mathrm{m}^{3}$ for seawater.

Despite the tremendous technological advances, a tidal turbine can extract only a fraction of this power, as shown in the following equation:

$P_{t}=P \cdot C_{p}=\frac{1}{2} \rho S C_{p} V_{m}^{3}$ 
In this study, we considered that the MCT is not pitched. Moreover, $C_{\mathrm{p}}$ can be approximated by an equation depending only on $\lambda$, which is defined as the ratio between $\Omega_{\mathrm{t}}$ and $V_{\mathrm{m}}$ :

$\lambda=\frac{\Omega_{t} \cdot R_{t}}{V_{m}}$

Mason-Jones et al. (2012) provided a relevant set of experimental data to validate the theoretical and numerical methods for MCT. In this study, we focused on the $C_{\mathrm{p}}$ curve according to $\lambda$, which is obtained from these experimental data when the turbine rotates at a uniform speed of $3.08 \mathrm{~m} / \mathrm{s}$ over a diameter of $20 \mathrm{~m}$. We notice that the data presented in Table 1 are extracted from this curve. On the basis of this table, we proposed the interpolation function of $C_{\mathrm{p}}$ to model the turbine. This function can be expressed as follows:

$$
\begin{aligned}
C_{p}= & a_{0}+a_{1} \cos (\lambda \times 0.174)+b_{1} \sin (\lambda \times 0.174) \\
& +a_{2} \cos (2 \times \lambda \times 0.174)+b_{2} \sin (2 \lambda \times 0.174) \\
& +a_{3} \cos (3 \times \lambda \times 0.174)+b_{3} \sin (3 \times \lambda \times 0.174) \\
& +a_{4} \cos (4 \times \lambda \times 0.174)+b_{4} \sin (4 \times \lambda \times 0.174)
\end{aligned}
$$

$C_{\mathrm{p}}$ can be considered a strong nonlinear function of $\lambda$.

Afterward, we implemented our interpolation function for modeling the turbine using the MATLAB Simulink environment. To validate our proposed model, in this work, we selected the turbine "Guinard Energies P66 3.5 kW." The obtained curve of $C_{\mathrm{p}}$ is shown in Figure 3. We notice that the maximum $C_{\mathrm{p}}$ value is 0.39 , which corresponds to a tip speed ratio of 3.67 to a marine current speed of $3 \mathrm{~m} / \mathrm{s}$. This value is considered the optimal tip speed ratio $\left(\lambda_{\text {opt }}\right)$ to achieve maximum power point tracking under rated marine current speeds.

\subsection{Model of the Mechanical Subsystem}

The mechanical subsystem (Figure 1(b)) is composed of the gearbox (drivetrain). The gearbox adjusts the speed of the

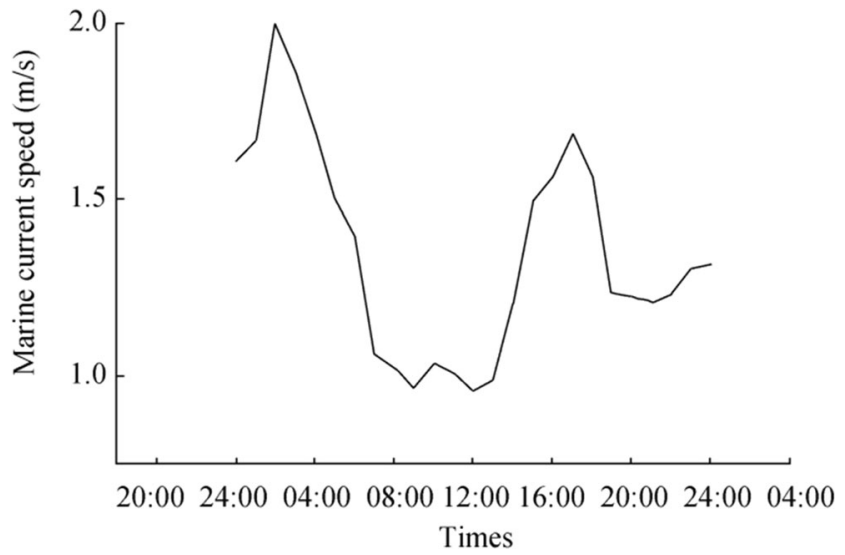

Figure 2 Marine current speed profile
Table 1 Experimental data of $C_{\mathrm{p}}$ and $\lambda$

\begin{tabular}{llll}
\hline$C_{\mathrm{p}}$ & $\lambda$ & $C_{\mathrm{p}}$ & $\lambda$ \\
\hline 0.035 & 0.65 & 0.39 & 3.88 \\
0.135 & 1.3 & 0.38 & 4.2 \\
0.2 & 1.62 & 0.364 & 4.51 \\
0.275 & 1.93 & 0.31 & 5.15 \\
0.355 & 2.59 & 0.27 & 5.51 \\
0.374 & 2.91 & 0.16 & 6.15 \\
0.4 & 3.6 & 0.08 & 6.5 \\
\hline
\end{tabular}

turbine to that of the generator through two shafts, namely, the slow shaft on the turbine side and the fast shaft on the generator side. In the literature, the two types of mechanical transmission models are rigid transmission and flexible transmission. The flexible transmission model attracted our attention because the mechanical coupling between the turbine and the electric machine is modeled using the two-mass model, as shown in Figure 1(b). The two masses are connected to a flexible shaft characterized by the elasticity coefficient of the drive shaft of the blades $k$ and the coefficient of friction of the shaft relative to the gearbox $d$. For wind turbines, this twomass model is sufficient to properly represent the dynamic behavior of the turbine (Fakharzadeh et al. 2013). For this purpose, the MCT drive system will be modeled using the two-mass model. Then, we write the following equations for the low-speed drivetrain:

$$
\left\{\begin{array}{c}
J_{\mathrm{t}} \frac{\mathrm{d} \Omega_{\mathrm{t}}}{\mathrm{dt}}=T_{\text {aer }}-T_{\text {mec }} \\
J_{\mathrm{G}} \frac{\mathrm{d} \Omega_{\mathrm{G}}}{\mathrm{dt}}=T_{\mathrm{mec}}-G_{\mathrm{g}} \cdot T_{\mathrm{em}} \\
\frac{\mathrm{d} T_{\mathrm{mec}}}{\mathrm{dt}}=k\left(\Omega_{\mathrm{t}}-\Omega_{\mathrm{g}}\right)+\mathrm{d}\left(\frac{\mathrm{d} \Omega_{\mathrm{t}}}{\mathrm{dt}}-\frac{\mathrm{d} \Omega_{\mathrm{G}}}{\mathrm{dt}}\right)
\end{array}\right.
$$

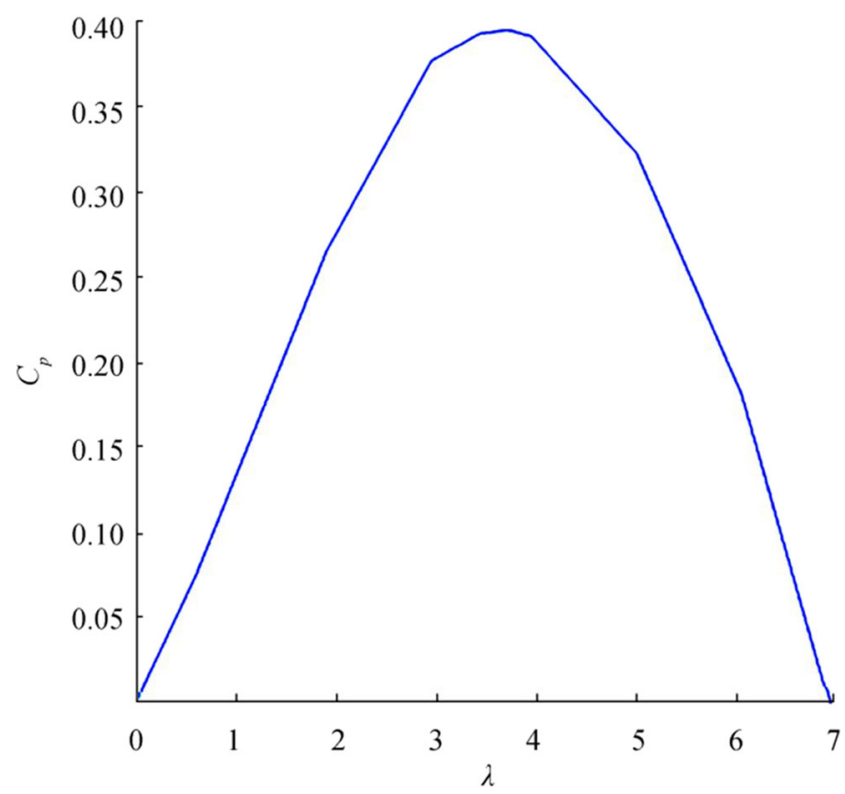

Figure $3 C_{\mathrm{p}}$ curve of the MCT 
where $J_{\mathrm{t}}$ and $\Omega_{\mathrm{t}}$ are the inertia and rotational speed of the turbine, respectively; $G_{\mathrm{g}}$ is the gain of gearbox; and $\Omega_{\mathrm{g}}$ and $J_{\mathrm{g}}$ are the rotational speed and inertia of the generator brought back to the low-speed shaft, respectively, which are defined as follows:

$$
\left\{\begin{array}{c}
\Omega_{\mathrm{G}}=\frac{\Omega_{\mathrm{g}}}{G_{\mathrm{g}}} \\
J_{\mathrm{G}}=G_{\mathrm{g}}^{2} \cdot J_{\mathrm{g}}
\end{array}\right.
$$

$T_{\text {aer }}$ is the aerodynamic torque extracted by the turbine, which is expressed as follows:

$T_{\mathrm{aer}}=k \times \Omega_{\mathrm{t}}^{2}$

where $K$ is derived as follows:

$K=\frac{\rho \pi \mathrm{R}_{t}^{5} C_{p}}{2 \lambda^{3}}$

Then, the nonlinear system (Eq. (6)) of the MCT can be expressed as follows:

$$
\left\{\begin{array}{c}
J_{t} \frac{\mathrm{d} \Omega_{t}}{\mathrm{dt}}=K \cdot \Omega_{t}^{2}-T_{\mathrm{mec}} \\
J_{G} \frac{\mathrm{d} \Omega_{G}}{\mathrm{dt}}=T_{\mathrm{mec}}-G_{g} \cdot T_{\mathrm{em}} \\
\frac{\mathrm{d} T_{\mathrm{mec}}}{\mathrm{dt}}=k\left(\Omega_{t}-\Omega_{g}\right)+\mathrm{d}\left(\frac{k \Omega_{t}^{2}-T_{\mathrm{mec}}}{J_{t}}-\frac{T_{\mathrm{mec}}+G_{g} T_{\mathrm{em}}}{J_{G}}\right)
\end{array}\right.
$$

\section{Linearized and State Representation of the MCT System}

Given that determining the optimal control for nonlinear systems is difficult, deriving a solution for an equivalent linear control system is necessary. For the MCT system, nonlinearity is detected in the aerodynamic torque $T_{\text {aer }}$. For this, we need to adopt a linearization approach for $T_{\text {aer }}$ (Eq. (8)) according to $\Omega_{\mathrm{t}}$.

The operating point corresponding to the marine current speed $V_{\mathrm{m}}$ is variable. Consequently, linearizing the MCT system around different operating points corresponding to the marine current speed $V_{\mathrm{m}}$ is possible. Thus, we can obtain the derivative of the system from an operating point given the marine current speed $V_{\mathrm{m}}$ :

$\Delta C_{\text {aer }}=\left.\frac{\delta C_{\text {aer }}}{\delta \Omega_{t}}\right|_{\text {op }} \Delta \Omega_{t}=\beta_{0} \Delta \Omega_{t}$

where

$\beta_{0}=\frac{\rho \pi R_{\mathrm{t}}^{3} V_{\mathrm{m}}^{2}}{2 \Omega_{t 0}}\left[\frac{\delta C_{\mathrm{p}}(\lambda)}{\delta \lambda}-\frac{C_{\mathrm{p} 0}}{\lambda_{0}}\right]$
The symbol $\Delta$ designates the variation according to the chosen operating point (OP). New state variables corresponding to the variations around the operating point are defined as follows:

$$
\begin{aligned}
& \Delta \Omega_{\mathrm{t}}=\Omega_{\mathrm{t}}-\Omega_{\mathrm{t} 0} \\
& \Delta \Omega_{\mathrm{G}}=\Omega_{\mathrm{G}}-\Omega_{\mathrm{G} 0} \\
& \Delta T_{\mathrm{mec}}=T_{\mathrm{mec}}-T_{\mathrm{mec} 0}
\end{aligned}
$$

On the basis of the preceding expressions, the linearization of the flexible model (Eq. (8)) around an operating point leads to the following equations:

$$
\left\{\begin{array}{c}
J_{t} \Delta \Omega_{t}=\beta_{0} \Delta \Omega_{t}-\Delta T_{\mathrm{mec}} \\
J_{G} \Delta \Omega_{G}=\Delta T_{\mathrm{mec}}-G_{g} \Delta T_{\mathrm{em}} \\
\Delta T_{\mathrm{mec}}=\left(K+\frac{d \beta_{0}}{J_{t}}\right) \Delta \Omega_{t}-K \Delta \Omega_{G}-d\left(\frac{1}{J_{t}}+\frac{1}{J_{G}}\right) \Delta T_{\mathrm{mec}}
\end{array}\right.
$$

The linearization of the nonlinear system around an operating point, expressed in Eq. (11), enabled us to express the state space model as follows:

$$
\begin{aligned}
{\left[\begin{array}{c}
\Delta \Omega_{t} \\
\Delta \Omega_{G} \\
\Delta C_{\mathrm{mec}}
\end{array}\right]=} & {\left[\begin{array}{ccc}
\frac{\beta_{0 i}}{J_{t}} & 0 & \frac{1}{J_{t}} \\
0 & 0 & \frac{1}{J_{g}-B V} \\
k+\frac{d \beta_{0}}{J_{t}} & -k & -d\left(\frac{1}{J_{t}}+\frac{1}{J_{G}}\right)
\end{array}\right]\left[\begin{array}{c}
\Delta \Omega_{t} \\
\Delta \Omega_{G} \\
\Delta C_{\mathrm{mec}}
\end{array}\right] } \\
+ & {\left[\begin{array}{c}
0 \\
\frac{G_{g}}{J_{G}} \\
\frac{d G_{g}}{J_{G}}
\end{array}\right] \Delta C_{\mathrm{em}} }
\end{aligned}
$$

In a more compact form, the system expressed in Eq. (14) can be rewritten as follows:

$\boldsymbol{x}=\boldsymbol{A x}+\boldsymbol{B u}$

where

$\boldsymbol{x}=\left[\begin{array}{c}\Delta \Omega_{\mathrm{t}} \\ \Delta \Omega_{\mathrm{G}} \\ \Delta C_{\mathrm{mec}}\end{array}\right], \boldsymbol{A}=\left[\begin{array}{ccc}\frac{\beta_{0 i}}{J_{\mathrm{t}}} & 0 & \frac{1}{J_{\mathrm{t}}} \\ 0 & 0 & \frac{1}{J_{\mathrm{g}}-B V} \\ k+\frac{d \beta_{0}}{J_{\mathrm{t}}} & -k & -d\left(\frac{1}{J_{\mathrm{t}}}+\frac{1}{J_{\mathrm{G}}}\right)\end{array}\right]$,

$\boldsymbol{B}=\left[\begin{array}{c}0 \\ \frac{G_{\mathrm{g}}}{J_{\mathrm{G}}} \\ \frac{d G_{\mathrm{g}}}{J_{\mathrm{G}}}\end{array}\right]$, and $\boldsymbol{u}=\Delta C_{\mathrm{em}}$ 
In Figure 4, we can distinguish four operating areas of a variable-speed MCT, in which the index $a_{1}$ of the matrix $A_{i, j}$ depends on the variation of the marine current:

1) Zones 1 and 4: The MCT does not provide any power because the marine current speed is lower than the start speed and higher than the rated speed. Thus, the MCT will be stopped.

2) Zone 2: For the low marine current speed $\left(V_{\mathrm{m}} \leq V_{\Omega \mathrm{t}-\mathrm{r}}\right)$ :

$A_{11}=\frac{-\rho \pi R_{\mathrm{t}}^{4} V_{\mathrm{m}} C_{\mathrm{pmax}}}{2 \lambda_{0}^{2} J_{t}}$

3) Zone 3: When the marine current speed is between $V_{\Omega \mathrm{t}-\mathrm{r}} \leq V_{\mathrm{m}} \leq V_{\mathrm{m}-\mathrm{r}}$ :

$$
A_{11}=\frac{\rho \pi R_{\mathrm{t}}^{3} V_{\mathrm{m}}^{2} C_{\mathrm{pmax}}}{2 J_{\mathrm{t}} \Omega_{\mathrm{t}-\mathrm{r}}}\left[\frac{\partial C_{\mathrm{P}}}{\partial \lambda}-\frac{C_{\mathrm{p}}}{\lambda}\right]
$$

\section{LQR Optimal Control}

The objective of optimal control has two main orientations. The first orientation aims to minimize energy, whereas the second orientation seeks to reduce the convergence time of the system. The general objective is to find the optimal control that minimizes the criterion that varies according to the orientation adopted. A large variety of optimal control techniques have been applied to the MCT in a permanent attempt to improve its function and benefit as much as possible from the energy that it can produce. Optimal control is the state feedback of a nonlinear time-invariant system with LQR that has evolved significantly in recent years. The principle of the LQR command is shown in Figure 5 (Khargonekar et al. 1990; Anderson et al. 2007; Athans and Falb 2013; Levine 2018).

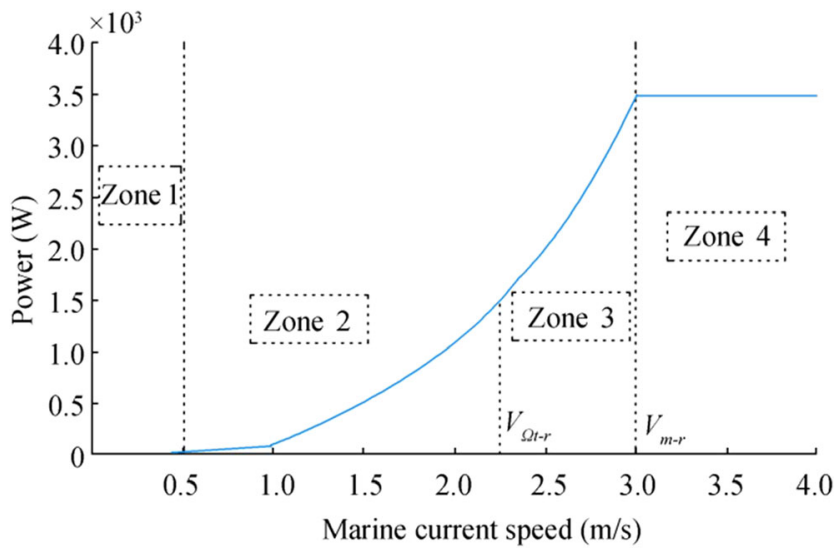

Figure 4 Control regions for a turbine controller

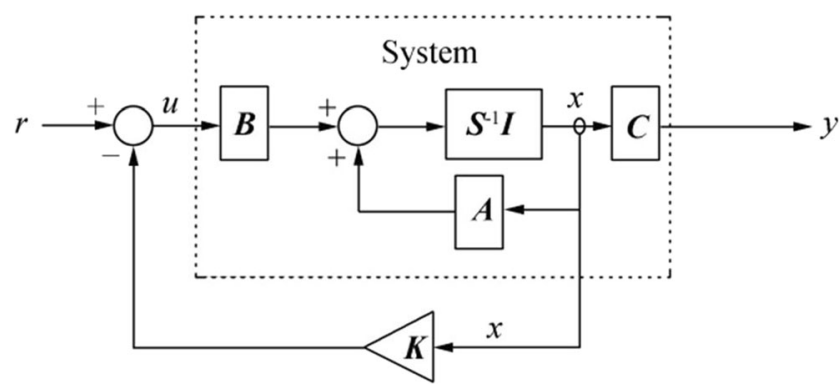

Figure 5 Principle of the LQR command

In general, the system model can be expressed as the following state space equation:

$$
\left\{\begin{array}{c}
\boldsymbol{x}=\boldsymbol{A x}(t)+\boldsymbol{B u}(t) \\
\boldsymbol{y}=\boldsymbol{C} \boldsymbol{x}(t)
\end{array}\right.
$$

where $\boldsymbol{x}(t) € \mathbb{R}^{n}$ denotes the state vector, $\boldsymbol{u}(t) € \mathbb{R}^{n}$ denotes the control vector, $\boldsymbol{y}(t) \in \mathbb{R}^{q}$ denotes the output vector, $\boldsymbol{A}$ is the matrix of evolution or state, $\boldsymbol{B}$ is the control or input matrix, and $\boldsymbol{C}$ is the output matrix or measured value. Moreover, the pair $(\boldsymbol{A}, \boldsymbol{B})$ is assumed to denote that the system is controllable. The process of the feedback regulator needs to follow the state space equation. The simplified problem of the LQR is to find the matrix of the corrector $\boldsymbol{K}$, which minimizes the function of the cost (or the criterion of performance), as follows:

$J=\frac{1}{2} \int_{0}^{\infty}\left(\boldsymbol{x}^{\mathrm{T}} \boldsymbol{Q} \boldsymbol{x}+\boldsymbol{u}^{\mathrm{T}} \boldsymbol{R} \boldsymbol{u}\right) \mathrm{d} t$

where the weighting matrices $\boldsymbol{Q}$ and $\boldsymbol{R}$ satisfy the following expression:

$\boldsymbol{Q}=\boldsymbol{Q}^{\mathrm{T}} \geq 0, \boldsymbol{R}=\boldsymbol{R}^{\mathrm{T}}>0$

The Hamiltonian system is written as follows:

$$
\begin{aligned}
H(\boldsymbol{x}, \boldsymbol{u}, \boldsymbol{p}, t)= & \boldsymbol{p}^{\mathrm{T}} \boldsymbol{A}(t) \boldsymbol{x}+\boldsymbol{p}^{\mathrm{T}} \boldsymbol{B}(t) \boldsymbol{u} \\
& +\frac{1}{2}\left(\boldsymbol{x}^{\mathrm{T}} \boldsymbol{Q}(t) \boldsymbol{x}+\boldsymbol{u}^{\mathrm{T}} \boldsymbol{R}(t) \boldsymbol{u}\right)
\end{aligned}
$$

The Hamiltonian system must satisfy the following conditions:

- The state equation:

$p=-\frac{\partial H}{\partial x}=-\boldsymbol{A}^{\mathrm{T}}(t) \boldsymbol{p}-\boldsymbol{Q}(t) \boldsymbol{x}$

- The absence of a constraint on the command:

$\frac{\partial H}{\partial u}=-\boldsymbol{B}^{\mathrm{T}}(t) \boldsymbol{p}-\boldsymbol{R}(t) \boldsymbol{u}=0$ 
From Eq. (21), we deduce the following expression:

$u_{\mathrm{opt}}=-\boldsymbol{R}^{-1}(t) \boldsymbol{B}^{\mathrm{T}} p(t)$

Then, the dynamic equation of the closed-loop system can be written as follows:

$\dot{x}=\boldsymbol{A}^{\mathrm{T}}(t) \boldsymbol{x}(t)-\boldsymbol{B}(t) \boldsymbol{R}^{-1}(t) \boldsymbol{B}^{\mathrm{T}}(t) \boldsymbol{p}(t)$

Equations (20) and (21) can be written in the form of a matrix system, which is also called the Hamiltonian system:

$$
\frac{\mathrm{d}}{\mathrm{d} t}\left(\begin{array}{c}
\boldsymbol{x}(t) \\
\boldsymbol{p}(t)
\end{array}\right)=\left(\begin{array}{cc}
\boldsymbol{A}(t) & -\boldsymbol{B}(t) \boldsymbol{R}^{-1}(t) \boldsymbol{B}^{\mathrm{T}} \\
-\boldsymbol{Q}(t) & -\boldsymbol{A}^{\mathrm{T}}(t)
\end{array}\right)\left(\begin{array}{c}
\boldsymbol{x}(t) \\
\boldsymbol{p}(t)
\end{array}\right)
$$

With $\boldsymbol{p}(t)=P(t) \boldsymbol{x}(t)$, Eq. (20) can be rewritten as follows:

$\dot{p}=-\left(A^{\mathrm{T}}(t) P(t)+\boldsymbol{Q}(t)\right) \boldsymbol{x}(t)=\dot{P} \boldsymbol{x}(t)+\dot{P}(t) \boldsymbol{x}(t)$

Equation (23) can be rewritten as follows:

$\left(\dot{P}+P \boldsymbol{A}+\boldsymbol{A}^{\mathrm{T}} P-P \boldsymbol{B} \boldsymbol{R}^{-1} \boldsymbol{B}^{\mathrm{T}} P+\boldsymbol{Q}\right) X=0$

$P$ is the positive solution (symmetric) to the algebraic Riccati equation (Eq. (26)):

$P+P \boldsymbol{A}+\boldsymbol{A}^{\mathrm{T}} P-P \boldsymbol{B} \boldsymbol{R}^{-1} \boldsymbol{B}^{\mathrm{T}} P+\boldsymbol{Q}=0$

Then, we derive the minimum criterion of the initial state $\left(x_{0}\right.$ at $\left.t_{0}\right)$ :

$J_{\min }=\frac{1}{2} x_{0}^{\mathrm{T}} P\left(t_{0}\right) x_{0}$

Notably, the optimal control obtained can be written as state feedback $\boldsymbol{u}=-\boldsymbol{K}(t) \boldsymbol{x}$, where:

$\boldsymbol{K}=-\boldsymbol{R}^{-1} \boldsymbol{B}^{\mathrm{T}} P$

\section{Control Objectives}

In this part, we developed the control laws that can be applied to zones 2 and 3 (Figure 4) on the basis of the marine current speed:

- When $V_{\mathrm{m}} \leq V_{\Omega_{\mathrm{t}-\mathrm{r}}}$, the main control objectives are as follows: The MCT starts to generate energy at a certain marine current speed. As result, the operation of the MCT is related to the low marine current speed. In this area, the control objective is to operate the turbine at maximum efficiency. To ensure that the power coefficient is maintained at the optimal value $C_{\mathrm{pmax}}=C_{\mathrm{p}}\left(\lambda_{0}\right), \lambda$ must reach its optimum value $\lambda_{0}$ (Figure 3 ). This means that the control in this area acts on the electromagnetic torque of the generator, which in turn acts on the rotational speed and reduces its variations from the reference value $\Omega_{\mathrm{t}-\mathrm{ref}}$, as expressed in Eq. (30).

The controller must minimize the fluctuations of the mechanical torque $T_{\text {mec }}$, which affects the quality of the electrical power generated (although this effect is less important in this area than in other areas). The reference equation for maximizing energy conversion is expressed as follows:

$\left\{\begin{array}{cc}\Omega_{T-r e f}=\frac{\lambda_{0} V_{m}}{R_{t}} ; & \text { for } V_{m} \leq V_{\Omega_{t-r}} \\ T_{\text {aero-ref }}=\frac{1}{2} \rho \pi R_{t}^{5} \Omega_{T-r e f}^{2} \frac{C_{p m a x}}{\lambda_{0}} ; & \text { for } V_{m} \leq V_{\Omega_{t-r}}\end{array}\right.$

- When $V_{\Omega_{\mathrm{t}-\mathrm{r}}} \leq V_{\mathrm{m}} \leq V_{\mathrm{m}-\mathrm{r}}$, the main control objectives are as follows: When the marine current reaches the value of $V_{\Omega_{\mathrm{t}-\mathrm{r}}}$, the MCT corresponds to the intermediate marine current speeds. In this area, the rotational speed of the turbine reaches its nominal value. The main control objective is to reduce the variations of $\Omega_{\mathrm{t}}$ from the nominal value $\Omega_{\mathrm{t}-\mathrm{r}}$ while acting on the electromagnetic torque. The reference equation for this area is expressed as follows:

$$
\left\{\begin{array}{ccc}
\Omega_{T-r e f}=\Omega_{t-r} ; & V_{\Omega_{t-r}} \leq V_{m} \leq V_{m-r} \\
C_{\text {aero-ref }}=\frac{1}{2} \rho \pi R_{t}^{5} \Omega_{T-r e f}^{2} \frac{C_{p-I}}{\lambda_{0}} ; & V_{\Omega_{t-r}} \leq V_{m} \leq V_{m-r}
\end{array}\right.
$$

with:

$\left\{\begin{array}{cc}\lambda_{0}=\frac{\Omega_{t-r} R_{t}}{V_{m}} ; & V_{\Omega_{t-r}} \leq V_{m} \leq V_{m-r} \\ C_{\mathrm{p} \max }=C_{p}\left(\lambda_{0}\right) ; & V_{\Omega_{t-r}} \leq V_{m} \leq V_{m-r}\end{array}\right.$

The reference values for the electromagnetic and mechanical torques in zones 1 and 2 are derived as follows:

$\left\{\begin{array}{l}T_{\text {em-ref }}=\frac{T_{\text {aero-ref }}}{G_{g}} \\ T_{\text {mec-ref }}=T_{\text {em-ref }}\end{array}\right.$

The linearization of the aerodynamic torque, as presented in Section 3, makes it possible to rewrite Eq. (14) in the following form:

$\left\{\begin{array}{c}\boldsymbol{x}=\boldsymbol{A} \boldsymbol{x}+\boldsymbol{B} \Delta T_{\mathrm{em}} \\ \boldsymbol{y}=\boldsymbol{x}\end{array}\right.$

The proposed control strategy aims to minimize the LQR:

$J=\frac{1}{2} \int_{0}^{\infty}\left(\boldsymbol{x}^{\mathrm{T}} \boldsymbol{Q} \boldsymbol{x}+\Delta T_{\mathrm{em}}^{\mathrm{T}} \boldsymbol{R} \Delta T_{\mathrm{em}}\right) \mathrm{d} t$ 


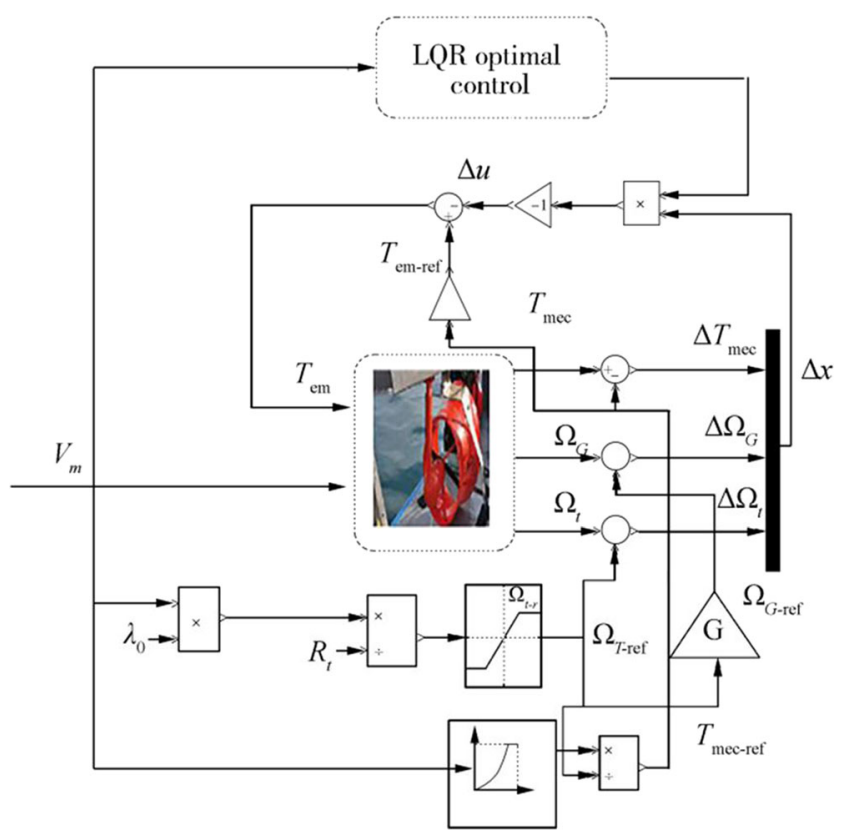

Figure 6 Block diagram of the system controlled during operation

Figure 6 presents the block diagram of the system controlled during operation.

\section{Simulation Results}

To validate our proposed control strategy based on the LQR approach, we conducted simulations using the MATLAB Simulink software. The simulation results of the MCT are depicted in Figure 7.

The considered system is a variable-speed, fixedpitch MCT with a nominal power rating of $3.5 \mathrm{~kW}$.
Table 2 Simulation parameters

\begin{tabular}{ll}
\hline Parameter & Value \\
\hline$\rho\left(\mathrm{kg} / \mathrm{m}^{3}\right)$ & 1000 \\
$R_{\mathrm{t}}(\mathrm{m})$ & 0.45 \\
$J_{\mathrm{t}}\left(\mathrm{kg} \mathrm{m}^{2}\right)$ & 0.1 \\
$J_{\mathrm{g}}\left(\mathrm{kg} \mathrm{m}^{2}\right)$ & 0.00196 \\
$G$ & 1.5 \\
$d$ & 0.02 \\
$k$ & 20 \\
\hline
\end{tabular}

Table 2 lists the values of the parameters used in the simulation.

The aim of the proposed control law is to minimize the quadratic criterion previously expressed in Eq. (35). The weight coefficients used in the quadratic criterion $J$ are derived as follows:

$\left\{\begin{array}{c}\boldsymbol{Q}=\left[\begin{array}{ccc}1 & 0 & 0 \\ 1 & 1000 & 0 \\ 1 & 0 & 1\end{array}\right] \\ R=[100]\end{array}\right.$

The resolution of Riccatti's equation (i.e., Eq. (34)) for the investigated system defines the control gain $\boldsymbol{K}$, which is previously expressed in Eq. (29). The result is the optimal state feedback, which is expressed in Eq. (37) or (38) in the following form:

$\Delta \boldsymbol{u}=-\boldsymbol{K}(t) \Delta \boldsymbol{x}$

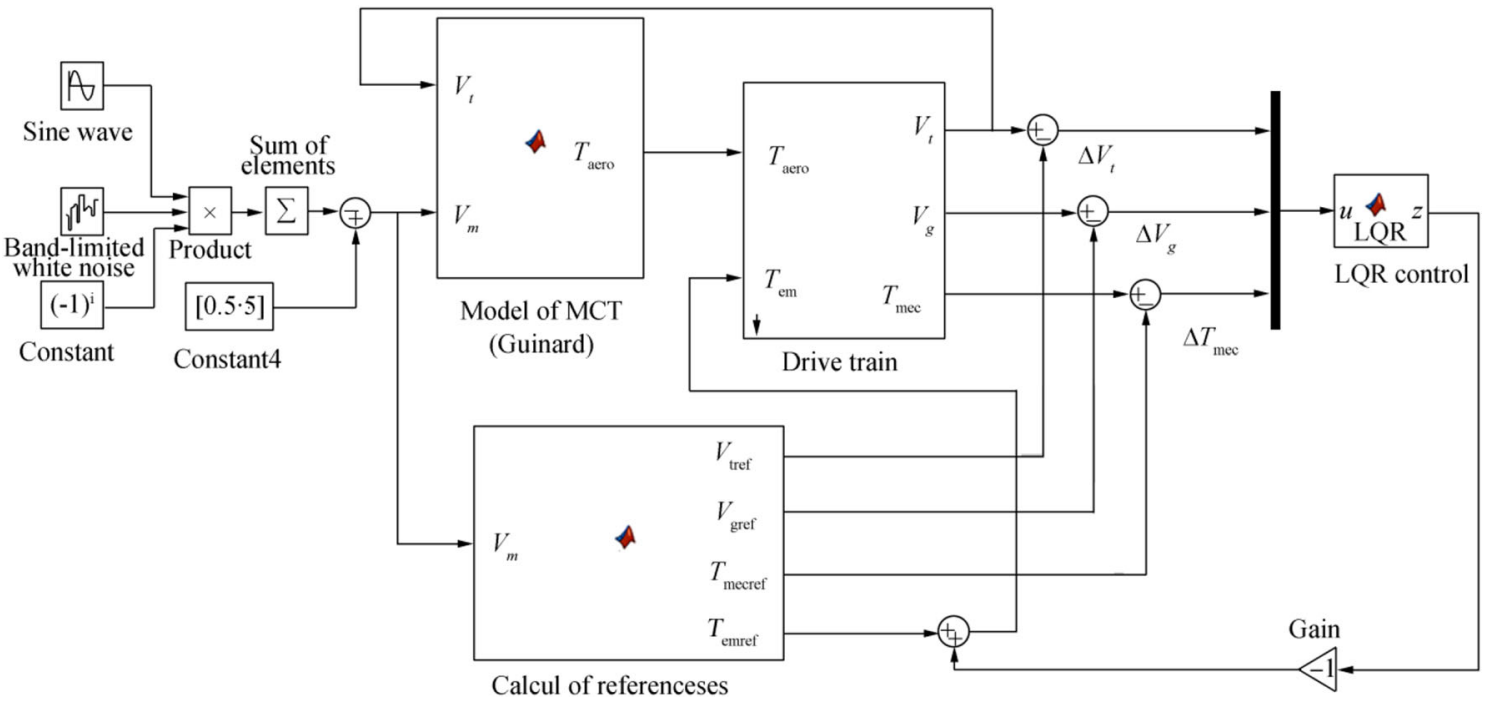

Figure 7 Simulation of the MCT system with LQR regulator using MATLAB Simulink 


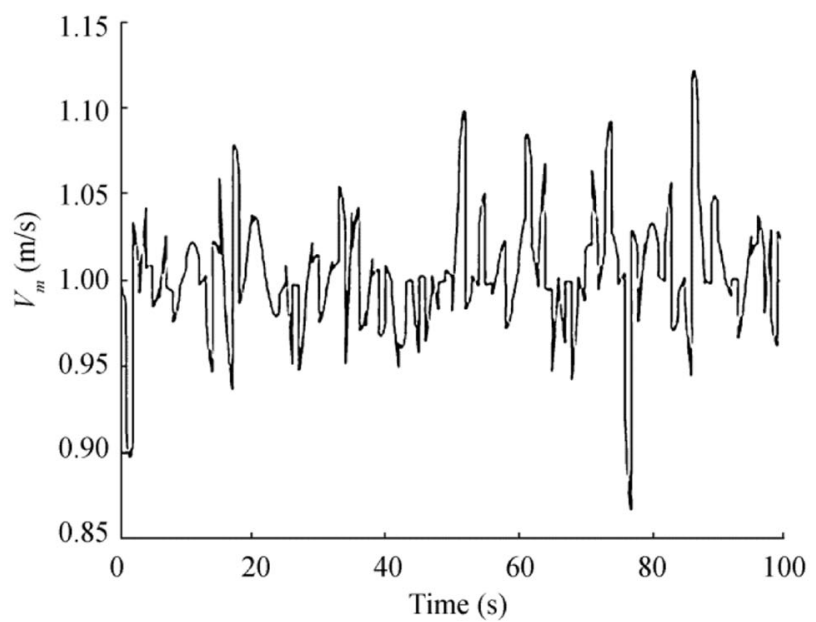

(a) $V_{m}$

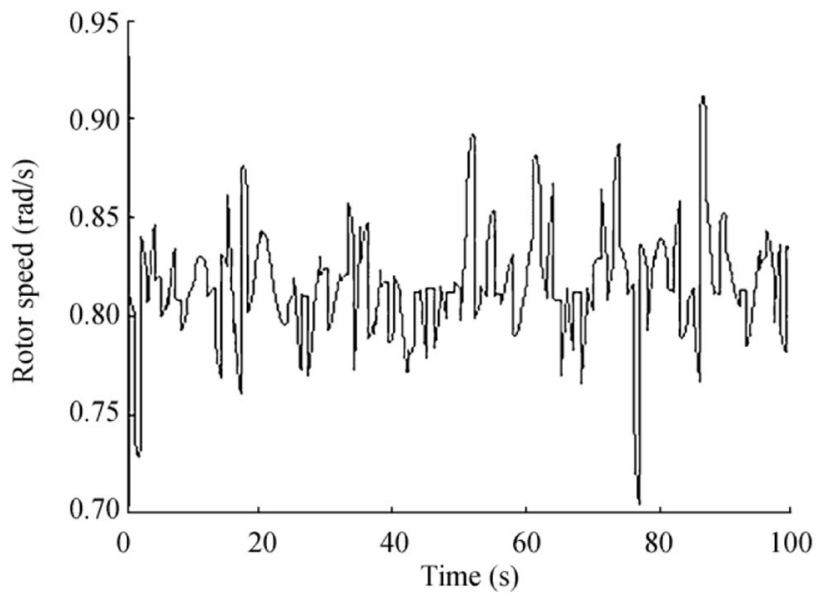

(b) Rotor speed

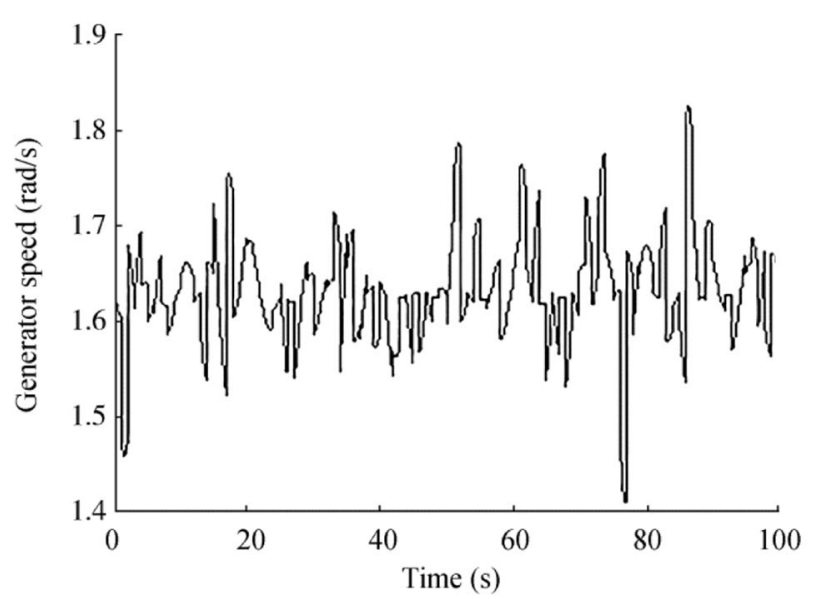

(c) Genreator speed

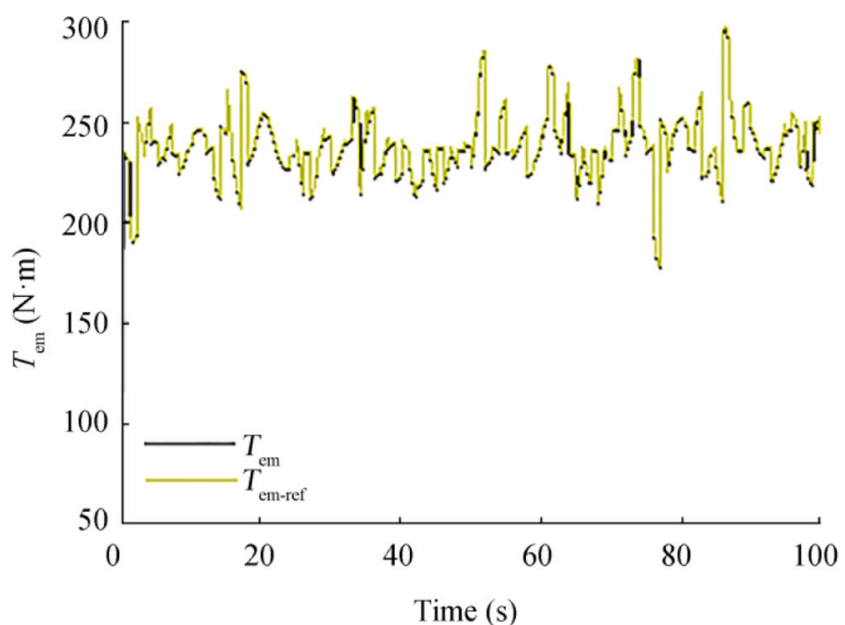

(d) $T_{\text {em }}$

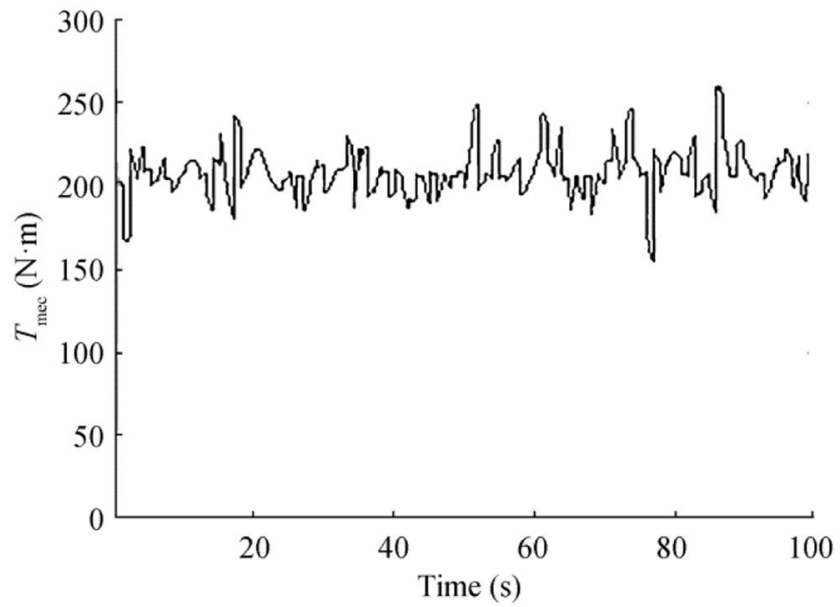

(e) $T_{\text {mec }}$

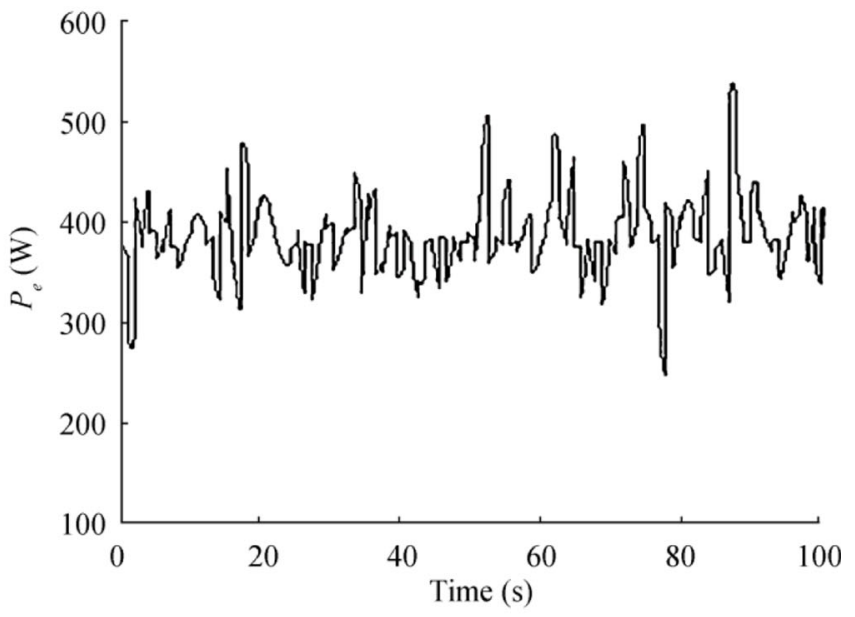

(f) $P_{e}$

Fig. 8 MCT speed variation and state and output variables in the partial load regime (zone 2) 


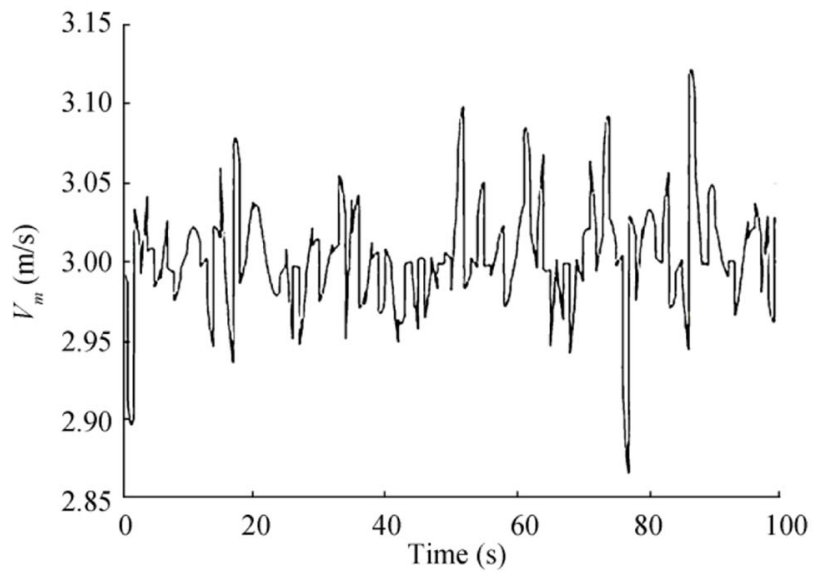

(a) $V_{m}$

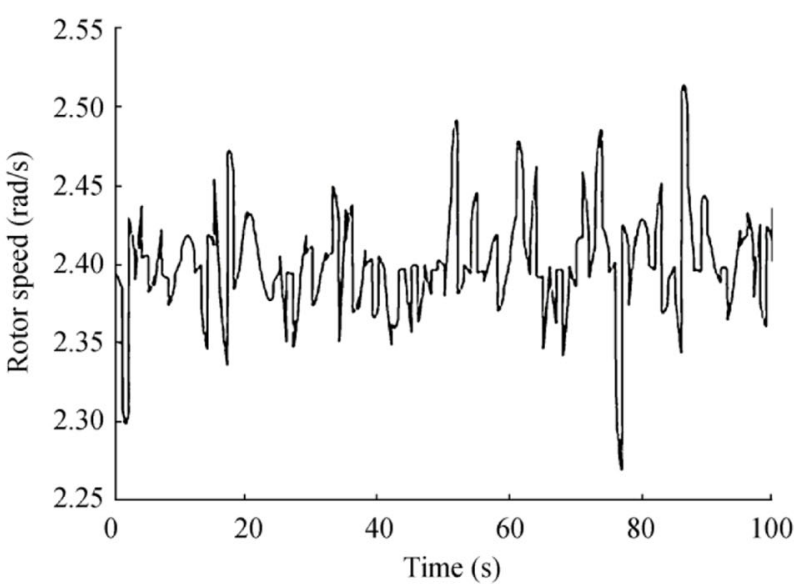

(b) Rotor speed

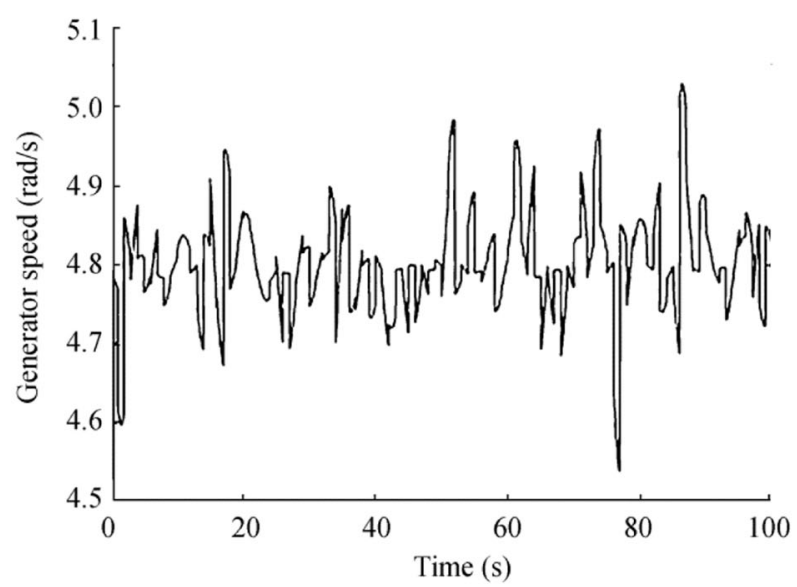

(c) Genreator speed

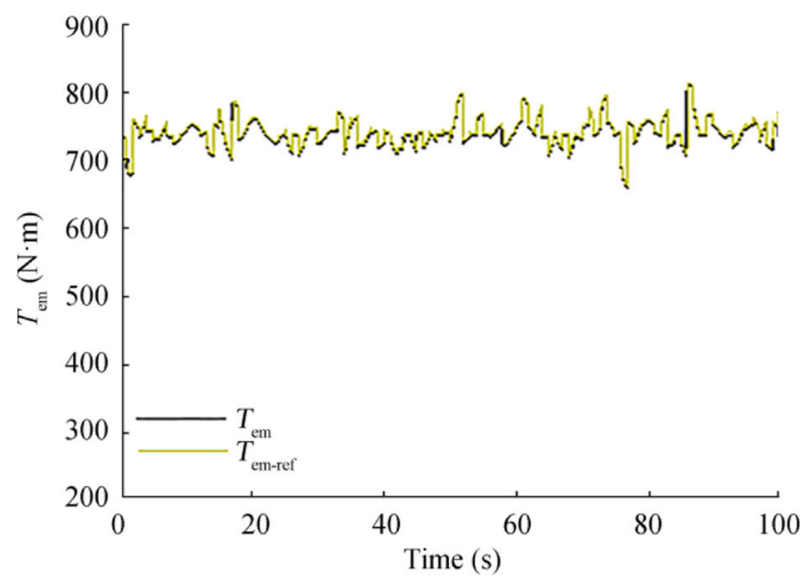

(d) $T_{\mathrm{em}}$

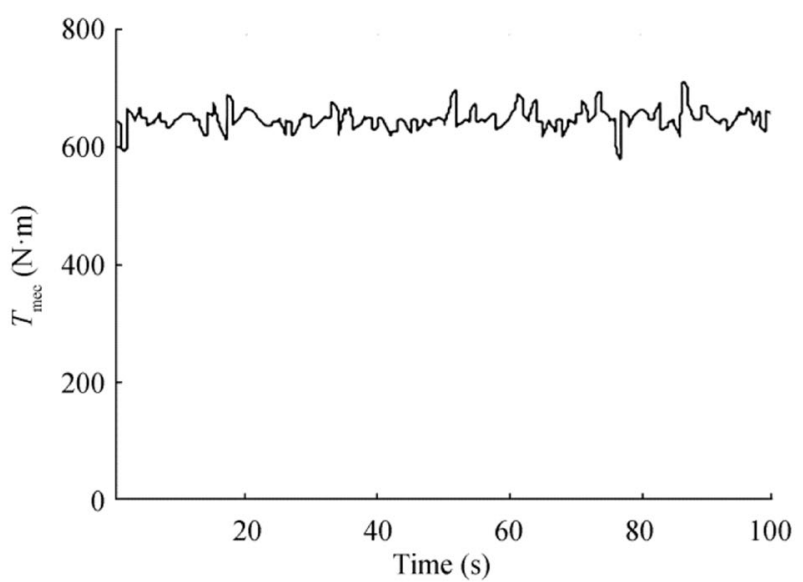

(e) $T_{\text {mec }}$

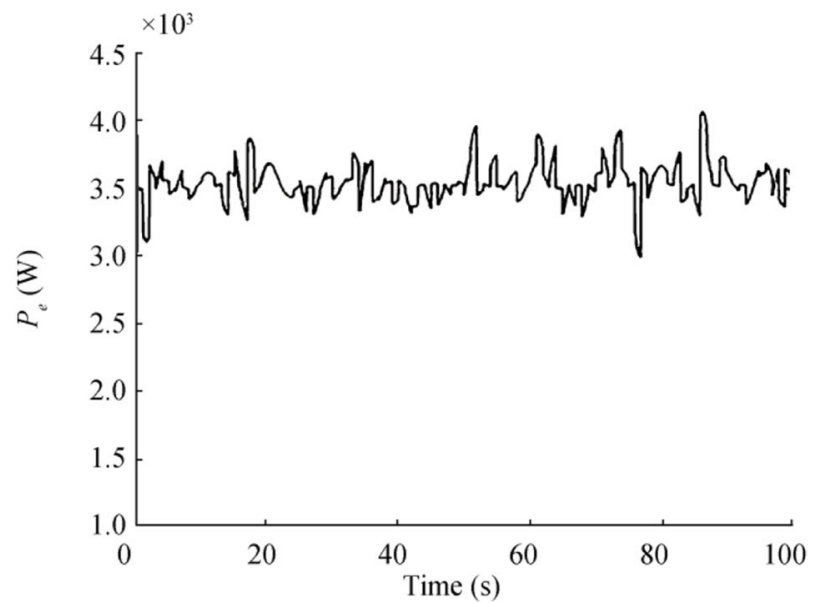

(f) $P_{e}$

Figure $9 \mathrm{MCT}$ speed variation and state and output variables in the partial load regime (zone 3) 
or

$\left\{\begin{array}{c}\Delta \boldsymbol{u}=\boldsymbol{u}-u_{\mathrm{ref}} ; \boldsymbol{u}=T_{\mathrm{em}} \\ \Delta \boldsymbol{x}=\boldsymbol{x}-x_{\mathrm{ref}} ; \boldsymbol{x}=\left[\begin{array}{c}\Omega_{t} \\ \Omega_{G} \\ T_{\mathrm{mec}}\end{array}\right]\end{array}\right.$

From this equation, we able to derive the following expression:

$T_{\mathrm{em}}=-\boldsymbol{K} \times \Delta \boldsymbol{x}+T_{\mathrm{em}-\mathrm{ref}}$

To illustrate the effectiveness of our proposed control system for a variable-speed MCT, we conducted two simulations of zones 2 and 3 . The results are presented in Figure 4.

\subsection{Partial Load Operation (Zone 2)}

In this simulation, we considered the low-speed MCT that corresponds to $V_{\mathrm{m}} \leq V_{\Omega_{\mathrm{t}-\mathrm{r}}}$. Figure 8 shows the different parameters that we have optimized to maximize the energy collected by the turbine. Figure 8 (a) presents the variation of the marine current velocity profile used to determine in which region control will be applied. Moreover, Figure 8 (d) shows that the proposed LQR control follows the reference values nearly perfectly, with a static error of 0 . Moreover, the gain provided by this control is equal to $\boldsymbol{K}=[0.2079-02896-0.0353]$ when $V_{\mathrm{m}}=1 \mathrm{~m} / \mathrm{s}$.

Figure 8 (b), (c), and (e) present the variations of three parameters, namely, rotor speed, generator speed, and mechanical torque, respectively. The LQR controller ensures that the system maintains the power coefficient at the optimal value $C_{\text {pmax }}$. As a result, the parametres can be optimized in zone 2 . Figure 8 (f) shows the variation of the electrical power according to generator speed and electromagnetic torque. Figure 8 (f) clearly shows that LQR maximizes the electrical power.

\subsection{Partial Load Operation (Zone 3)}

In this simulation, the rotational speed of the MCT reaches its rated value that corresponds to $V_{\Omega_{\mathrm{t}-\mathrm{r}}} \leq V_{\mathrm{m}} \leq V_{\mathrm{m}-\mathrm{r}}$. Figure 9 shows the different parameters that we have optimized to maintain the turbine at its optimum speed. In addition, these parameters enable the generator to turn at a speed that does not fluctuate rapidly (minimize the transient load). Figure 9 (a) presents the variation of the marine current velocity profile used to determine in which region control will be applied. In this case, a marine current profile with the average value of $V_{\mathrm{m}}=3 \mathrm{~m} / \mathrm{s}$ was imposed.

Figure 9 (d) shows that our proposed LQR control can be applied to zone 3, with a good performance in terms of electromagnetic torque. Furthermore, from this figure, we notice that the static error is always equal to 0 and the gain provided by this control is equal to $K=[0.1851-0.2899-0.0337]$ at $V_{\mathrm{m}}$ $=3 \mathrm{~m} / \mathrm{s}$.

Figure 9 (b), (c), and (e) show the variations of three parameters, namely, rotor speed, generator speed, and mechanical torque, respectively. We notice that the LQR controller can ensure that the system maintains the rotational speed at the nominal value. Consequently, the simulation results indicate that these three parameters have been optimized with the use of LQR control. In addition, Figure 9 (f) presents the variation of the output power of the MCT. We notice that the value of this parameter decreases from the nominal value to $3.5 \mathrm{~kW}$ because we used the LQR control.

On the basis of the simulation results obtained for zones 2 and 3, we confirm that our proposed LQR control can be set and used to act only on the electromagnetic torque to automatically regulate the different parameters of the MCT system, such as rotor speed, generator speed, and mechanical torque.

\section{Conclusions}

In this study, we proposed the LQR optimal controller approach coupled with the reference model of the outputs for the variable-speed MCT. Our solution maximizes power capture where the tidal speed is greater or less than the nominal speed.

In the first step, we introduced the differential equations for modeling the state space representation, which connects the outputs and controls to ensure better precision, and the reference model of the outputs whose main role is to impose the desired dynamic on the response of the system's outputs, including the power produced, whose response should be rapid.

In the second step, the LQR command, which involves minimizing the quadratic criterion that takes into consideration all of the variables of the system, was presented. Furthermore, the LQR command can ensure the best compromise between the desired performance and the feedback of the command. This principle of criterion minimization leads us to determine the optimal control structure of the state feedback for the linearized MCT system around different operating points.

The obtained simulation results enabled us to conclude that our linear control can provide a satisfactory performance in terms of following the reference values for any marine current speed nearly perfectly. In future work, we will focus on the application of more sophisticated control strategies to deal with the influence of any marine current speed by considering the entire system.

Nomenclature $V_{\mathrm{m}}$, marine current speed, $\mathrm{m} / \mathrm{s} ; \rho$, water density, $\mathrm{kg} / \mathrm{m}^{3}$; $R_{\mathrm{t}}$, rotor radius, $\mathrm{m} ; P$, aerodynamic power, $\mathrm{W} ; T_{\text {aer }}$, aerodynamic torque, $\mathrm{N} \cdot \mathrm{m} ; P_{\mathrm{e}}$, electrical power, $\mathrm{W} ; \lambda$, tip speed ratio; $C_{\mathrm{p}}$, power coefficient; $\Omega_{\mathrm{t}}$, rotor speed, $\mathrm{rad} / \mathrm{s} ; \Omega_{\mathrm{g}}$, generator speed, $\mathrm{rad} / \mathrm{s} ; \Omega_{\mathrm{tt}}$, low-speed shaft, $\mathrm{rad} / \mathrm{s}$; $J_{\mathrm{t}}$, rotor inertia, $\mathrm{kg} \cdot \mathrm{m}^{2} ; J_{\mathrm{g}}$, generator inertia, $\mathrm{kg} \cdot \mathrm{m}^{2} ; d$, damping 
coefficient, $\mathrm{N} \cdot \mathrm{m} /(\mathrm{rad} \cdot \mathrm{s}) ; k$, stiffness coefficient, $\mathrm{N} \cdot \mathrm{m} / \mathrm{rad} ; \Omega_{\mathrm{t}-\mathrm{r}}$, rotor rated speed; $G$, gearbox gain; $T_{\text {em }}$, generator torque, $\mathrm{N} \cdot \mathrm{m} ; T_{\text {mec }}$, mechanical torque, $\mathrm{N} \cdot \mathrm{m}$; MCT, marine current turbine; LQR, linear quadratic regulator

Open Access This article is licensed under a Creative Commons Attribution 4.0 International License, which permits use, sharing, adaptation, distribution and reproduction in any medium or format, as long as you give appropriate credit to the original author(s) and the source, provide a link to the Creative Commons licence, and indicate if changes were made. The images or other third party material in this article are included in the article's Creative Commons licence, unless indicated otherwise in a credit line to the material. If material is not included in the article's Creative Commons licence and your intended use is not permitted by statutory regulation or exceeds the permitted use, you will need to obtain permission directly from the copyright holder. To view a copy of this licence, visit http://creativecommons.org/licenses/by/4.0/.

\section{References}

Anderson DO, Anderson John B (2007) Optimal control: linear quadratic methods. Research School of information Sciences and Engineering. Dover Publications, Inc, Mineola, New York, pp 262-282

Antonova G, Nardi M, Scott A, Pesin M (2012). Distributed generation and its impact on power grids and microgrids protection. In Protective Relay Engineers, College Station, TX, USA, 152-161. DOI : https://doi.org/10.1109/CPRE.2012.6201229

Anvari M, Lohmann G, Wachter M, Milan P, Lorenz E, Heinemann D, Peinke J (2016) Short term fluctuations of wind and solar power systems. New Journal of Physics 18(6):063027-061-15. https:// doi.org/10.1088/1367-2630/18/6/063027

Athans M, Falb PL (2013) Optimal control: an introduction to the theory and its applications, Dover Publications, Inc. Mineola, New York, pp 364-424

Barrera-Cardenas R, Molinas M (2012) Optimal LQG controller for variable speed wind turbine based on genetic algorithms. Energy Procedia 20:207-216. https://doi.org/10.1016/j.egypro.2012.03.021

Bassi H, Mobarak YA (2017) State-space modeling and performance analysis of variable-speed wind turbine based on a model predictive control approach. Engineering, Technology \& Applied Science Research 7(2):1436-1443

Bayat F, Bahmani H (2017) Power regulation and control of wind turbines: LMI-based output feedback approach. International Transactions on Electrical Energy Systems 27(12):e2450. https:// doi.org/10.1002/etep. 2450

Benelghali S, Benbouzid MEH, Charpentier JF (2012) Generator systems for marine current turbine applications: a comparative study. IEEE Journal of Oceanic Engineering 37(3):554-563. https://doi.org/10. 1109/JOE.2012.2196346

Blackmore T, Myers LE, Bahaj AS (2016) Effects of turbulence on tidal turbines: implications to performance, blade loads, and condition monitoring. International Journal of Marine Energy 14:1-26. https://doi.org/10.1016/j.ijome.2016.04.017

Boukhezzar B, Siguerdidjane H (2010) Comparison between linear and nonlinear control strategies for variable speed wind turbines. Control Engineering Practice 18(12):1357-1368. https://doi.org/10.1016/j. conengprac.2010.06.010

Boukhezzar B, Siguerdidjane H (2011) Nonlinear control of a variablespeed wind turbine using a two-mass model. IEEE Transactions on Energy Conversion 26(1):149-162. https://doi.org/10.1109/TEC. 2010.2090155

Chen H, Tang T, Ait-Ahmed N, Benbouzid MEH, Machmoum M, Zaïm MEH (2018) Attraction, challenge and current status of marine current energy. IEEE Access 6:12665-12685. https://doi.org/10. 1109/ACCESS.2018.2795708

Chen H, Tang T, Han J, Ait-Ahmed N, Machmoum M, Zaim MEH (2019) Current waveforms analysis of toothed pole Doubly Salient Permanent Magnet (DSPM) machine for marine tidal current applications. International Journal of Electrical Power \& Energy Systems 106:242-253. https://doi.org/10.1016/j.jepes.2018.10.005

Einrí AN, Jónsdóttir GM, Milano F (2019). Modeling and control of marine current turbines and energy storage systems. International Federation of Automatic Control 2019, Jeju, 52(4), 425-430. DOI: https://doi.org/10.1016/j.ifacol.2019.08.247

Fakharzadeh A, Jamshidi F, Talebnezhad L (2013) New approach for optimizing energy by adjusting the trade-off coefficient in wind turbines. Energy, Sustainability and Society 3(1):3-19. https://doi. org/10.1186/2192-0567-3-19

Fox CJ, Benjamins S, Masden EA, Miller R (2018) Challenges and opportunities in monitoring the impacts of tidal-stream energy devices on marine vertebrates. Renewable and Sustainable Energy Reviews 81:1926-1938. https://doi.org/10.1016/j.rser.2017.06.004

Frost C, Morris CE, Mason-Jones A, O'Doherty DM, O'Doherty T (2015) The effect of tidal flow directionality on tidal turbine performance characteristics. Renewable Energy 78:609-620. https://doi. org/10.1016/j.renene.2015.01.053

Gaamouche A, Redouane A, El H, Belhorma B, Kchikach M, Jeffali F (2018) Review of technologies and direct drive generator systems for a grid connected marines current turbine. J. Mater. Environ. Sci. 9(9):2631-2644

Hodur RM (1997) The Naval Research Laboratory is coupled ocean/ atmosphere mesoscale prediction system (COAMPS). Monthly Weather Review 125(7):1414-1430. https://doi.org/10.1175/15200493(1997)125<1397:LSIOTC>2.0.CO;2

Jena D, Rajendran S (2015) A review of estimation of effective wind speed based control of wind turbines. Renewable and Sustainable Energy Reviews 43:1046-1062. https://doi.org/10.1016/j.rser.2014. 11.088

Khargonekar PP, Petersen IR, Zhou K (1990) Robust stabilization and $\mathrm{H}_{\infty}$ optimal control. IEEE Trans:356-361. https://doi.org/10.1109/9. 50357

Khettache L (2019). Contribution à l'Amélioration des Performances Des Systèmes Eoliens. PhD thesis, Universite Mohamed Khider Biskra, A1-141.

Kumar A, Stol K (2010) Simulating feedback linearization control of wind turbines using high-order models. Wind Energy 13(5):419 432. https://doi.org/10.1002/we.363

Kumar V, Pandey AS, Sinha SK (2016). Grid integration and power quality issues of wind and solar energy system: a review. Emerging Trends in Electrical Electronics \& Sustainable Energy Systems (ICETEESES-16), Sultanpur City, India ,71-80. DOI: https://doi.org/10.1109/ICETEESES.2016.7581355

Levine WS (2018) Control system advanced methods. Second Edition. The Control Systems Handbook, Boca Raton, pp 17-24. https://doi. org/10.1201/9781315218694

Liu J, Gao Y, Geng S, Wu L (2016). Nonlinear control of variable speed wind turbines via fuzzy techniques. IEEE Access, 5, 27-34. DOI : 0.1109/ACCESS.2016.2599542

Mahmoud MS, Oyedeji MO (2016) Optimal control of wind turbines under islanded operation. Intelligent Control and Automation 8(1): 1-14. https://doi.org/10.4236/ica.2017.81001

Mason-Jones A, O'doherty DM, Morris CE, O'doherty T, Byrne CB, Prickett PW, Poole RJ (2012) Non-dimensional scaling of tidal stream turbines. Energy 44(1):820-829. https://doi.org/10.1016/j. energy.2012.05.010

Melikoglu M (2018) Current status and future of ocean energy sources: a global review. Ocean Engineering 148:563-573. https://doi.org/10. 1016/j.oceaneng.2017.11.045 
Mycek P, Gaurier B, Germain G, Pinon G, Rivoalen E (2014) Experimental study of the turbulence intensity effects on marine current turbines behaviour. Part I: one single turbine. Renewable Energy 66:729-746. https://doi.org/10.1016/j.renene.2013.12.036

Omkar K, Karthikeyan KB, Srimathi R, Venkatesan N, Avital EJ, Samad A, Rhee SH (2019) A performance analysis of tidal turbine conversion system based on control strategies. Energy Procedia 160:526533. https://doi.org/10.1016/j.egypro.2019.02.202

Pham HT, Bourgeot JM, Benbouzid M (2017) Fault-tolerant finite control set-model predictive control for marine current turbine applications. IET Renewable Power Generation 12(4):415-421. https://doi. org/10.1049/iet-rpg.2017.0431

Prasad S, Purwar S, Kishor N (2019) Non-linear sliding mode control for frequency regulation with variable-speed wind turbine systems. International Journal of Electrical Power \& Energy Systems 107: 19-33. https://doi.org/10.1016/j.ijepes.2018.11.005

Qian P, Feng B, Liu H, Tian X, Si Y, Zhang D (2019) Review on configuration and control methods of tidal current turbines. Renewable and Sustainable Energy Reviews 108:125-139. https://doi.org/10. 1016/j.rser.2019.03.051

Rourke FO, Boyle F, Reynolds A (2010) Marine current energy devices: current status and possible future applications in Ireland. Renewable and Sustainable Energy Reviews 14(3):1026-1036. https://doi.org/ 10.1016/j.rser.2009.11.012

Seck A, Moreau L, Benkhoris MF, Machmoum M (2018). Control strategies of five-phase PMSG-rectifier under two open phase faults for current turbine system. 2018 IEEE International Power Electronics and Application Conference and Exposition (PEAC), Shenzhen, 16. DOI : / https://doi.org/10.1109/PEAC.2018.8590645

Thiébaut M, Sentchev A (2015) Estimation of tidal stream potential in the Iroise Sea from velocity observations by high frequency radars. Energy Procedia 76:17-26. https://doi.org/10.1016/j.egypro.2015. 07.835

Toumi S, Benelghali S, Trabelsi M, Elbouchikhi E, Amirat Y, Benbouzid M, Mi-mouni MF (2017) Modeling and simulation of a PMSGbased marine current turbine system under faulty rectifier conditions. Electric Power Components \& Systems 45(7):715-725. https://doi.org/10.1080/15325008.2017.1293197

Zhou Z, Scuiller F, Charpentier JF, Benbouzid M, Tang T (2013). Power limitation control for a PMSG-based marine current turbine at high tidal speed and strong sea state. Electric Machines \& Drives Conference (IEMDC), Chicago, 75-80. DOI : https://doi.org/10. 1109/IEMDC.2013.6556195 